\title{
Numerical analysis of an oscillating water column converter considering a physical constraint in the chimney outlet
}

\section{Mateus das Neves Gomes ${ }^{1,2, *}$, Flávio Medeiros Seibt ${ }^{3}$, Luiz Alberto Oliveira Rocha ${ }^{2,3,4}$, Elizaldo Domingues dos Santos ${ }^{3,4}$ and Liércio André Isoldi ${ }^{3,4}$}

1 Instituto Federal de Educação, Ciência e Tecnologia do Paraná (IFPR)

2 Programa de Pós-Graduação em Engenharia Mecânica (PROMEC) - Universidade Federal do Rio Grande do Sul (UFRGS)

3 Programa de Pós-Graduação em Engenharia Oceânica (PPGEO) - Escola de Engenharia (EE), Universidade Federal do Rio Grande (FURG), Av. Itália km 8, CEP 96203-900, Rio Grande-RS, Brazil.

4 Programa de Pós-Graduação em Modelagem Computacional (PPGMC) - Escola de Engenharia (EE), Universidade Federal do Rio Grande (FURG), Av. Itália km 8, CEP 96203-900, Rio Grande-RS, Brazil.

* Corresponding Author: mateus.gomes@ifpr.edu.br

\begin{abstract}
This work presents a 2D numerical study of an Oscillating Water Column (OWC) converter considering physical constraints in its outlet chimney to represent the turbine pressure drop. Two strategies were adopted. The first considers different dimensions for a physical constraint similar to an orifice plate, being the analysis performed in a laboratory scale. After that, other physical restriction with geometry similar to a rotor turbine was investigated in a real scale by means a dimensional variation. The numerical results indicate the importance of consider the pressure drop caused by turbine in the analysis of the OWC behavior.
\end{abstract}

\section{Keyw ords}

Wave Energy, Oscillating Water Column (OWC), Volume of Fluid (VOF), Pressure drop, Turbine.

\section{Nomenclature}

$\begin{array}{ll}C_{T} & \text { Wave tank length } \\ d & \text { Physical constraint length } \\ d_{l} & \text { Physical constraint diameter } \\ \vec{g} & \text { Gravitational acceleration } \\ H & \text { Wave height } \\ H_{T} & \text { Wave tank height } \\ H_{1} & \text { OWC chamber height } \\ H_{2} & \text { OWC chimney height } \\ H_{3} & \text { Lip submergence } \\ h & \text { Water depth } \\ L & \text { OWC chamber length } \\ l & \text { Chimney outlet diameter } \\ p & \text { Static pressure }\end{array}$

$\begin{array}{ll}N & \text { Turbine rotation speed } \\ T & \text { Wave period } \\ t & \text { Time } \\ \vec{v} & \text { Velocity vector } \\ x & \text { Horizontal direction } \\ y & \text { Normal direction to the } x \text {-z plane } \\ z & \text { Vertical direction } \\ \alpha & \text { Volume fraction } \\ \lambda & \text { Wave length } \\ \mu & \text { Viscosity } \\ \pi & \text { Mathematical constant } \\ \rho & \text { Density } \\ = & \\ \tau & \text { Stress tensor }\end{array}$




\section{$1 \quad$ Introduction}

Nowadays the countries are investing in the exploration of new energy sources, especially in those called renewable energy sources. Among several ways to obtain energy from renewable sources, the conversion of the ocean waves energy into electrical one can be an attractive alternative for countries with large coastal regions such as Brazil. The wave power is proportional to its squared amplitude and its period, so waves with high amplitude (around $2 \mathrm{~m}$ ) and high periods (between 7 and $10 \mathrm{~s}$ ) normally exceed $50 \mathrm{~kW}$ per meter of wave front (Cruz and Sarmento, 2004). The criterion used to classify the Wave Energy Converters (WEC), in most references, is associated with the installation depth of the device. In this context, the WEC are classified in: Onshore devices (with access by earth), Nearshore devices (in depths between 8 and $20 \mathrm{~m}$ ), and Offshore devices (in depths higher than $20 \mathrm{~m}$ ). Other possible classification is related with the main operational principle of the wave energy converters, i.e., the converters type. The principal converter types are: Oscillating Water Column (OWC) devices, Floating Bodies devices, and Overtopping devices (Cruz and Sarmento, 2004

In the present work the main operational principle of OWC converters is numerically studied. The purpose here is to consider in the computational model a physical constraint in the chimney outlet mimicking the effect of the turbine over the fluid-dynamic behavior of the OWC chamber, allowing future investigations about the influence of the turbine over the design of the OWC chamber. An analogous approach was already employed by Liu et. al (2009).

The computational domains, composed by the OWC inserted into a wave tank, were generated in GAMBIT software. The numerical simulations were performed in FLUENT software, which is a Computational Fluid Dynamic (CFD) package based on the Finite Volume Method (FVM). More details about the FVM can be found in Versteeg and Malalasekera (2007). The Volume of Fluid (VOF) multiphase model was adopted to treat adequately the water-air interaction. The VOF model was developed by Hirt and Nichols (1981) and it was already used in other numerical studies related with wave energy, e.g., Horko (2007), Liu et. al (2008a), Liu et. al (2008b), Gomes (2010), Ramalhais (2011), Liu et. al (2011) and Dos Santos et al. (2013). Besides, regular waves are generated in the wave tank, reaching the OWC converter and generating an alternate air flow through its chimney.

Therefore, to study the influence of the pressure drop imposed by the turbine in the OWC fluid-dynamic behavior two different strategies were adopted. Firstly, adopting regular waves in laboratory scale, a restriction similar to a orifice plate was considered in the outlet of the OWC chimney causing a physical constraint in the air flow that cross the chimney. Six dimensions for the opening were tested, allowing the achievement of a curve generated by the relation between two non dimensional parameters: pressure drop and flow coefficients. Other authors also studied these coefficients, as Weber and Thomas (2001), Ramalhais (2011) and Carija et al. (2012). Afterwards, the second strategy also uses a physical constraint, however in this case the constraint is positioned in a way that causes a peripheral air flow in the chimney outlet. Several dimensions for the physical restriction were investigated for regular waves in real scale. From this analysis, it was possible to identify the best constraint dimension, i.e., the dimension that provides the highest power take-off (PTO) available in the OWC chimney. So, taking into account this best restriction dimension, the OWC was submitted to a real wave spectrum.

In the sequence of the paper a brief explanation about the OWC main operational principle is performed, followed by the computational modeling description, information about the physical constrains, results and discussion, and conclusions.

\section{Oscillating water column (OWC)}

An Oscillating Water Column (OWC) device is a steel or concrete structure with a chamber presenting at least two openings, one in communication with the sea and one with the atmosphere (Fig. 1). Under the action of waves the free surface inside the chamber oscillates and displaces the air above the free surface. The air is thus forced to flow through a turbine that generates electrical power (Nielsen et al., 2006). Usually a Wells turbine is employed; such turbines, once started, turn in the same direction to extract power from air flowing in either axial direction, i.e., the turbine motion is independent of the fluid flow direction (Twidell and Weir, 2006).

The greatest disadvantage of the OWC converter is the large dimensions of structure. As a result, the cost of a single device is rather high (Khaligh and Onar, 2010). An advantage of using the OWC device for power extraction is that the air speed is increased by reduction in the cross-sectional area of the channel approaching the turbine. This couples the slow motion of the waves to the fast rotation of the turbine without mechanical gearing (Twidell and Weir, 2006).

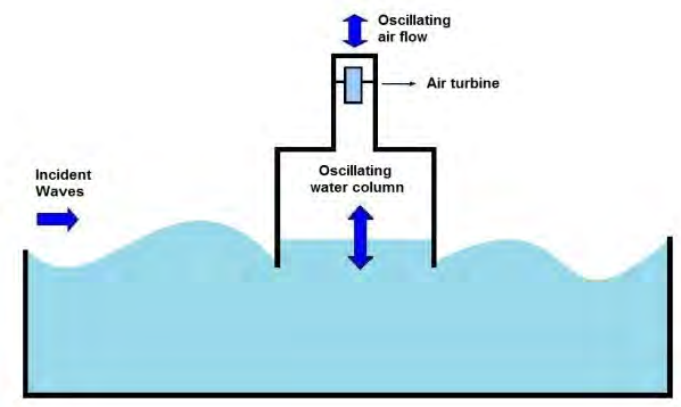

Fig. 1 Oscillating water column (OWC) converter.

Another important advantage is that the moving mechanical parts, that is, the turbine and the generator, are not in direct contact with water (Khaligh and Onar, 2010). 


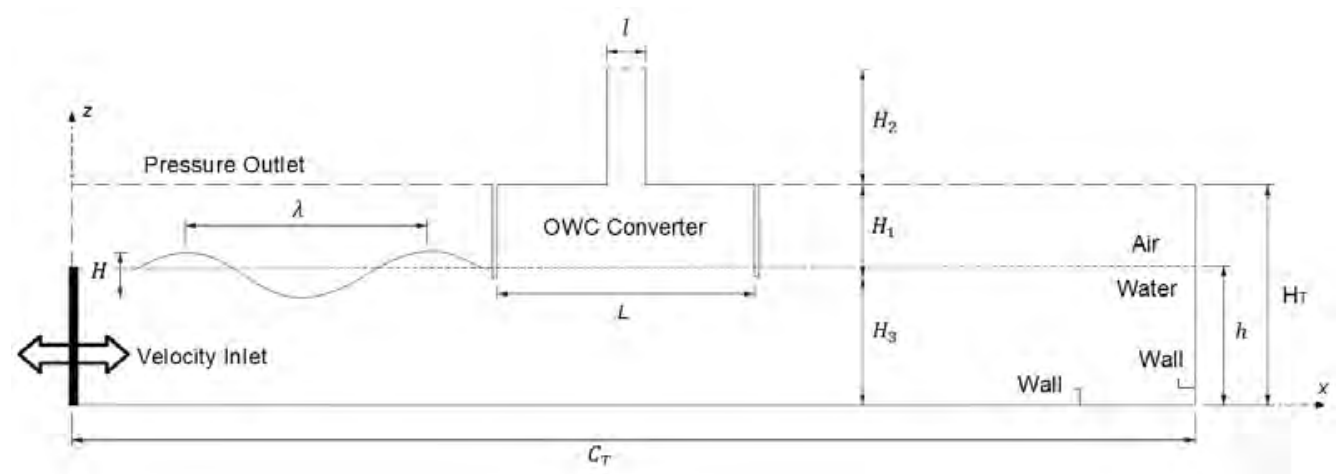

Fig. 2 Schematic representation of the 2D computational domain.

\section{Computational modeling}

Starting from the definition of the main wave parameters - period $(T)$, height $(H)$, and water depth $(h)$ - it is possible to determine the length $\left(C_{T}\right)$ and height $\left(H_{T}\right)$ of the wave tank, as can be seen in Fig. 2. In addition, the OWC dimensions in agreement with the characteristics of the incident waves must be defined, completing the computational domain geometry (Fig. 2).

Thus, to apply the first proposed strategy (similar to an orifice plate) to investigate the pressure drop imposed to the OWC converter by the turbine, wave parameters and the wave tank dimensions in a laboratory scale are presented in Tab. 1.

Table 1. Wave characteristics and dimensions of the tank in laboratory scale.

\begin{tabular}{|l|c|}
\hline \multicolumn{1}{|c|}{ Characteristic } & Value \\
\hline Wave period $(T)$ & $0.80 \mathrm{~s}$ \\
\hline Wave height $(H)$ & $0.14 \mathrm{~m}$ \\
\hline Wavelength $(\lambda)$ & $1.00 \mathrm{~m}$ \\
\hline Water depth $(h)$ & $0.50 \mathrm{~m}$ \\
\hline Length of wave tank $\left(C_{T}\right)$ & $5.00 \mathrm{~m}$ \\
\hline Height of wave tank $\left(H_{T}\right)$ & $0.80 \mathrm{~m}$ \\
\hline Submergence of OWC $\left(H_{3}\right)$ & $0.465 \mathrm{~m}$ \\
\hline
\end{tabular}

The other dimensions need to complete the computational domain geometry in this first analysis are indicated in Fig. 2 and their values were defined according with the optimal geometry found in Gomes et al. (2012), being: $L=0.4082 \mathrm{~m}$, $l=0.1414 \mathrm{~m}, H_{1}=0.3429 \mathrm{~m}, H_{2}=0.4242 \mathrm{~m}, H_{3}=0.465 \mathrm{~m}$, $H_{2} / l=3.0$, and $H_{1} / L=0.84$.

As already mentioned, a physical restriction similar to an orifice plate is inserted on the outlet OWC chimney, aiming to represent the pressure drop caused by a turbine. The orifice plate was inserted for all cases in the middle of the chimney $\left(\mathrm{H}_{2} / 2\right)$. Thus, it is possible to evaluate the effects caused by the presence of a turbine in the fluid-dynamic behavior of the OWC converter. Six different values for the physical constraint were tested, as showed in Fig. 3. (a)

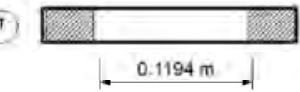

(2)

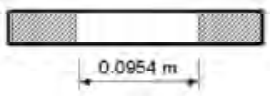

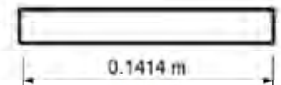

(3)
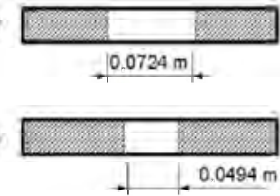

(5)

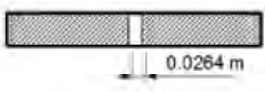

Fig. 3 Dimensions for the physical constraint represented by an orifice plate.

The second strategy adopted in this work to reproduce the pressure drop imposed by a turbine in the OWC device also uses a physical restriction, however unlike the orifice plate this constraint promote a peripheral air flow similar to the effect of the flow over a rotor hub (see the geometry in Fig. 4). It is worth to mention that this air flow behavior, flowing peripherally and surrounding the physical restriction, presents a similarity with a real air flow over a turbine. Besides, the use of this geometry in studies concerned with the influence of the turbine in the OWC behavior is an original proposal of the present work. In Fig. 4 it is depicted a sketch indicating the form and location of this physical restriction. The dimensions $d$ and $d_{1}$ represents the length and the diameter of the constraint, respectively.

Moreover, as a real scale is adopted in this second strategy, the dimensions of the OWC were defined as: $L=16.7097 \mathrm{~m}$, $l=2.3176 \mathrm{~m}, H_{1}=2.2501 \mathrm{~m}, H_{2}=6.9529 \mathrm{~m}, H_{3}=9.50 \mathrm{~m}$, $H_{1} / L=0.1346, H_{2} / l=3.00$. These values correspond to the best shape obtained in Gomes et al. (2013), where a geometric optimization investigation was carried out. 


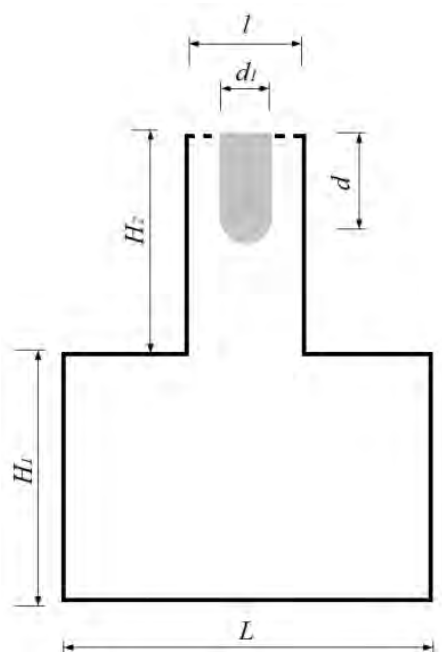

Fig. 4 OWC converter and physical constraint with geometry similar to a turbine in real scale.

A real wave spectrum consisting of nine waves was considered here, being the wave and wave tank characteristics indicated in Tab. 2.

For all waves of the spectrum (Tab. 2) the following parameters are kept constant: wave height $(H)$ of $1.0 \mathrm{~m}$, water depth $(h)$ of $10.0 \mathrm{~m}$, and tank height $\left(H_{T}\right)$ of $12.0 \mathrm{~m}$. So, taking into account the first wave of the spectrum, i.e., the wave with $T=5.0 \mathrm{~s}$ of Tab. 2, the dimensions of the physical constraint were varied as showed in Tab. 3 . Highlighting that in these numerical simulations $0<d_{1}<l$; and that the $d$ dimension is also variable, being its value obtained by: $d=\left(1+d_{1} / 2\right) \mathrm{m}$.

Table 2 Wave spectrum.

\begin{tabular}{|c|c|c|}
\hline Period $(T)$ & Wave length $(\lambda)$ & Tank length $\left(C_{T}\right)$ \\
\hline $5.0 \mathrm{~s}$ & $37.6 \mathrm{~m}$ & $188.0 \mathrm{~m}$ \\
\hline $6.0 \mathrm{~s}$ & $48.5 \mathrm{~m}$ & $242.5 \mathrm{~m}$ \\
\hline $7.0 \mathrm{~s}$ & $60.0 \mathrm{~m}$ & $300.0 \mathrm{~m}$ \\
\hline $7.5 \mathrm{~s}$ & $65.4 \mathrm{~m}$ & $327.0 \mathrm{~m}$ \\
\hline $8.0 \mathrm{~s}$ & $71.0 \mathrm{~m}$ & $355.0 \mathrm{~m}$ \\
\hline $9.0 \mathrm{~s}$ & $81.8 \mathrm{~m}$ & $409.0 \mathrm{~m}$ \\
\hline $10.0 \mathrm{~s}$ & $92.0 \mathrm{~m}$ & $460.0 \mathrm{~m}$ \\
\hline $11.0 \mathrm{~s}$ & $103.0 \mathrm{~m}$ & $515.0 \mathrm{~m}$ \\
\hline $12.0 \mathrm{~s}$ & $113.3 \mathrm{~m}$ & $566.5 \mathrm{~m}$ \\
\hline
\end{tabular}

Table 3 Dimensions of the physical constraint.

\begin{tabular}{|c|c|c|}
\hline Case & Constraint diameter $\left(d_{l}\right)$ & Constraint length $(d)$ \\
\hline 1 & $0.3176 \mathrm{~m}$ & $1.1588 \mathrm{~m}$ \\
\hline 2 & $0.7176 \mathrm{~m}$ & $1.3588 \mathrm{~m}$ \\
\hline 3 & $1.1176 \mathrm{~m}$ & $1.5588 \mathrm{~m}$ \\
\hline 4 & $1.5176 \mathrm{~m}$ & $1.7588 \mathrm{~m}$ \\
\hline 5 & $1.9176 \mathrm{~m}$ & $1.9588 \mathrm{~m}$ \\
\hline 6 & $2.1176 \mathrm{~m}$ & $2.0588 \mathrm{~m}$ \\
\hline
\end{tabular}

Therefore, based on the numerical results generated taking into account the values of Tab. 3, the constraint dimensions that promoted a better harnessing of the incident waves was defined as the optimal geometry of the physical constraint. Thus, this optimal shape was submitted to all waves of the spectrum (Tab. 2).

\subsection{Boundary conditions}

One can note in Fig. 2 that the generation of waves is performed by the imposition of the wave velocities components as boundary conditions (by means of an User Defined Function (UDF) in FLUENT software) in the left side of the computational domain. This numerical methodology to generate regular waves was already verified and validated in Horko (2007), Gomes et al. (2009) and Seibt et al. (2014) and Dos Santos et al. (2013). It is worth to mention that in accordance with Chakrabarti (2005) the wave adopted in the first strategy is classified as a high order wave, while the waves employed for the second strategy are linear waves.

The other boundary conditions are the atmospheric pressure in the dashed lines of Fig. 2 and the no slip condition (wall) in the continuous lines of Fig. 2.

\subsection{Mathematical model}

As previously mentioned, the computational domain is composed by a wave tank in which the converter is coupled (Fig. 2). Besides, to obtain a more realistic interaction among water, air and converter the multiphase Volume of Fluid (VOF) model (Hirt and Nichols, 1981) is adopted.

The VOF is a multiphase model used to solve fluid flow problems with two or more immiscible fluids. In this formulation, all phases are well defined and the volume occupied by one phase cannot be occupied by the other. Thus, to represent these phases inside of each control volume is necessary to consider the volume fraction $(\alpha)$ concept. Hence it is necessary that the sum of all phases for each cell be always equal to one. In this work there are only two phases: water and air. Therefore if $\alpha=1$ the cell is full of water; if $\alpha$ $=0$ the cell is without water, i.e., it is filled of air; and if the value of $\alpha$ is between 0 and 1 the cell contain the interface between water and air (Srinivasan et al., 2011).

Moreover, when the VOF method is used a single set of momentum and continuity equations is applied to all fluids, and the volume fraction of each fluid in every computational cell (control volume) is tracked throughout the domain by the addition of a transport equation for the volume fraction. Thus, the model is composed by the continuity equation (FLUENT, 2007; Grimmler et al., 2012):

$\frac{\partial \rho}{\partial t}+\nabla \cdot(\rho \vec{v})=0$ 
the volume fraction equation

$$
\frac{\partial(\alpha)}{\partial t}+\nabla \cdot(\alpha \vec{v})=0
$$

and momentum equations:

$$
\frac{\partial}{\partial t}(\rho \vec{v})+\nabla \cdot(\rho \vec{v} \vec{v})=-\nabla p+\nabla \cdot(\mu \bar{\tau})+\rho \vec{g}
$$

being: $\rho$ the fluid density, $t$ the time, $\vec{v}$ the flow velocity vector, $p$ is the static pressure, $\mu$ the molecular viscosity, $\tau$ the stress tensor and $\vec{g}$ the gravitational acceleration.

The momentum and continuity equations are solved for the mixture of both phases (air and water). Then, it is necessary to evaluate average values for density and viscosity, respectively (Srinivasan et al., 2011):

$$
\begin{aligned}
& \rho=\alpha \rho_{\text {water }}+(1-\alpha) \rho_{\text {air }} \\
& \mu=\alpha \mu_{\text {water }}+(1-\alpha) \mu_{\text {air }}
\end{aligned}
$$

\subsection{Numerical procedures}

As earlier mentioned, the conservation equations of mass and momentum and the equation for transport of volume fraction are solved with the finite volume method (FVM). The solver is pressure-based, employing upwind and PRESTO for spatial discretizations of momentum and pressure, respectively. The velocity-pressure coupling is performed by the PISO algorithm, while the GEO-RECONSTRUCTION method is employed to tackle with the volumetric fraction. Moreover, under-relaxation factors of 0.3 and 0.7 are imposed for the conservation equations of continuity and momentum, respectively (Gomes et al., 2012).

\section{$4 \quad$ Results and discussion}

\subsection{Strategy 1 (orifice plate)}

In this first approach the six dimensions for the physical constraint in the OWC chimney outlet (Fig. 3) were numerically simulated. In all simulations a regular mesh generated by square cells with side of $0.01 \mathrm{~m}$ and a time step of $0.001 \mathrm{~s}$ were adopted to reproduce the incidence of eight waves $(4.8 \mathrm{~s}$ ) over the OWC device. During this time of $4.8 \mathrm{~s}$ there is no effects caused by the wave reflection since the length of the wave tank is $C_{T}=5.0 \mathrm{~m}$. Besides, the wave propagation is considered stabilized when $t \geq 2.4 \mathrm{~s}$, i.e., after the formation of the third wave.

The presence of these restrictions promotes a pressure drop in the region where it should be located the turbine as well as a significant increase in the pressure inside the hydro-pneumatic chamber of the OWC, as one can observe in Fig. 5.

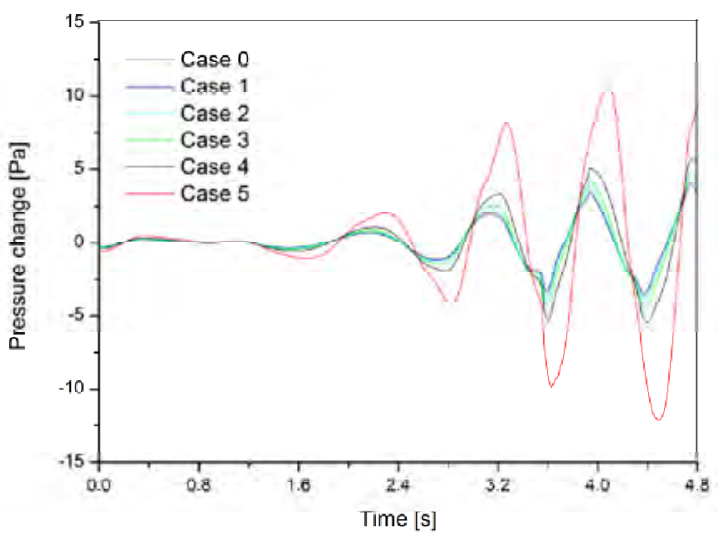

Fig. 5 Pressure inside the OWC chamber as a function of time.

Figure 5 indicates that if the physical constraint dimension increases a higher pressure variation is observed. The pressure drop is estimated by the difference between the pressure inside the OWC chamber (which is monitored in several points) and the pressure in the outlet region of the chimney (which is monitored by a sensor placed in this region).

Accordingly, non dimensional coefficients related with the pressure and the flow rate in the OWC converter can be evaluated as follow (Carija et al. (2012):

$$
\begin{aligned}
& \psi=\frac{\Delta p}{\rho_{a} N^{2} D^{2}} \\
& \Phi=\frac{\dot{m}}{\rho_{a} N D^{3}}
\end{aligned}
$$

where: $\Delta p$ is the pressure drop, $m$ is the mass flow rate, $\rho_{a}$ is the air density, $N$ is the speed of the turbine rotation, and $D$ is the turbine diameter. Considering average values for the pressure and mass flow rate, which were obtained by application of the Root Mean Square (RMS) technique (Gomes et al., 2012) in the transient numerical results, the pressure drop coefficient is depicted as a function of flow coefficient in Fig. 6.

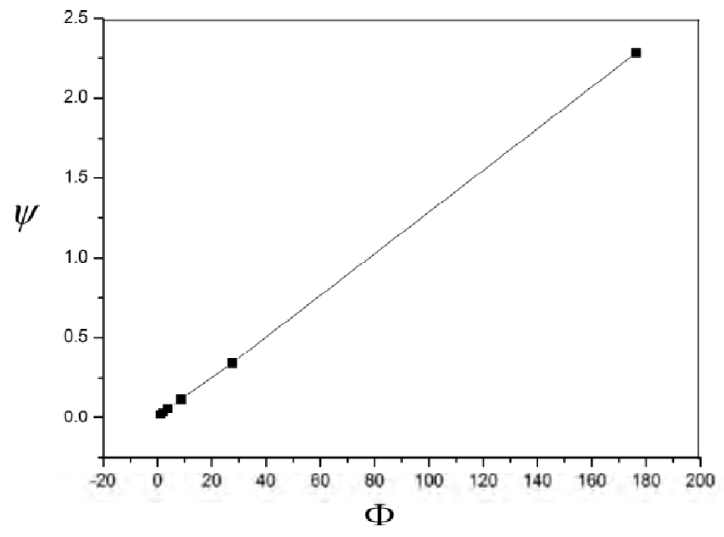

Fig. 6 Pressure drop coefficient as a function of the flow coeficcient - Strategy 1 (laboratory scale). 
Figure 6 allows to verify that there is a linear relation adjusted from the obtained points between the pressure drop coefficient and flow coefficient: $\Phi=K \Psi$, being $K=0.42$. This type of relation is similar to that found in experimental and numerical works of Wells turbine, see Ramalhais (2011).

After that, it was analyzed the velocity behavior in the region where the physical restriction was placed. As one can note in Fig. 7 , the increase of the constraint causes an augmentation in the air flow velocity as well as a higher pressure drop, in a linear behavior. For this relation between velocity and pressure average values were considered, being these values linearly fitted with a maximum error of $4 \%$.

In Fig. 8 the velocity behavior inside the OWC device is presented for all studied cases in the instant $t=4.0 \mathrm{~s}$ showing that the velocity increases as the constraint increases, especially in the constraint region. It is also noticed a significant modification of the fluid flow inside the chamber.

In all simulations the OWC dimensions were kept constant, excepting the constraint dimension which vary for each case. These results obtained with the strategy of reproducing the turbine effect over the OWC air flow by means a physical restriction presented allows its utilization in a satisfactory way, i.e., imposing the pressure drop that would be caused by the turbine.

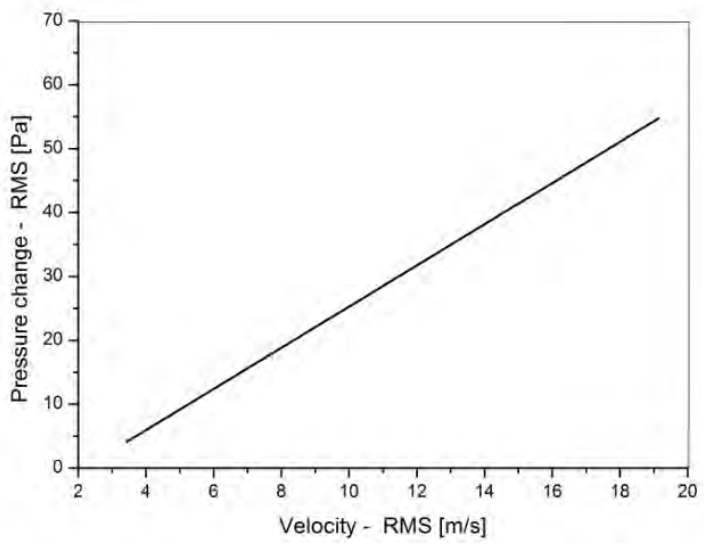

Fig 7 Velocity versus pressure drop.

\subsection{Strategy 2 (rotor hub geometry)}

This second strategy aims to test a physical restriction considering a more realistic geometry (Fig. 2), similar to the rotor hub geometry, in the OWC chimney. Hence, the behavior of the air flow when passing through the turbine and hence the pressure drop will also be more realistic. To do so, it were tested several dimensions for this constraint, as presented in Tab. 3, allowing to assess the relation between flow and pressure drop coefficients which occurs in the turbine of OWC device. As earlier mentioned, it was taken into account an OWC converter with constant dimensions, being only varied the physical constraint diameter, in accordance with Tab. 3 and submitted to the first regular wave of Tab. 2. Posteriorly, only the best shape among the above cases was submitted to the wave spectrum indicated in Tab. 2. In these numerical simulations the mesh characteristics and the solution parameters are the same employed in Gomes et. al (2013).

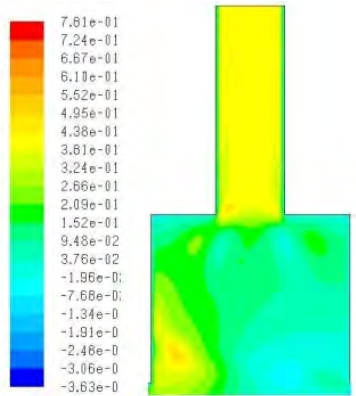

(a)
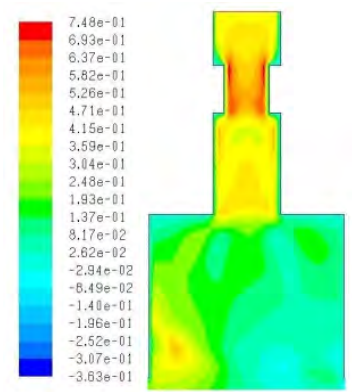

(c)

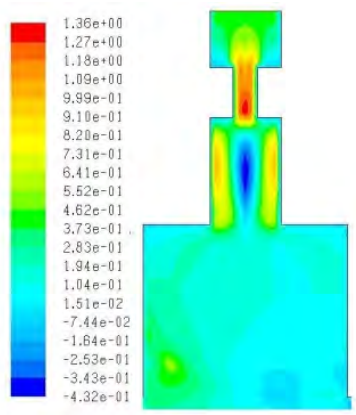

(e)

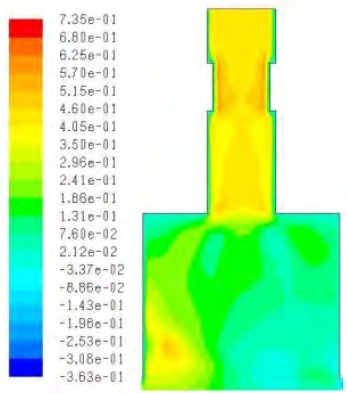

(b)

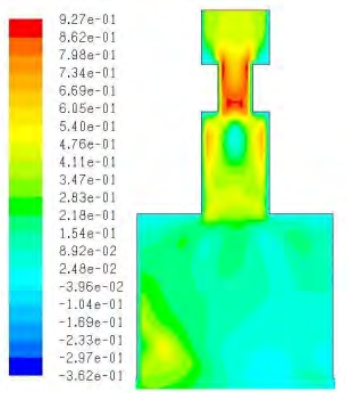

(d)

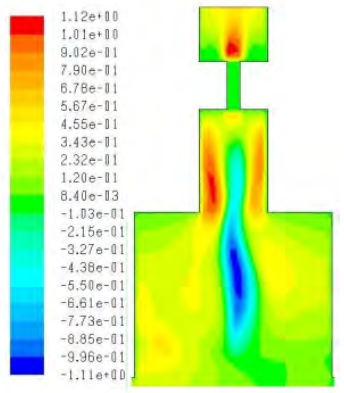

(f)
Fig 8. Velocity behavior on the instant $t=4.0 \mathrm{~s}$ for: (a) case 0 , (b) case 1 , (c) case 2, (d) case 3, (e) case 4, (f) case 5 .

As expected, the decrease of the region through which the air flows by the constraint increase makes the internal pressure of the OWC converter also increases and hence occurring a power augmentation, as can be noted in Tab. 4. It is important to mention that the values of Tab. 4 are obtained by the RMS technique, evaluated in the interval time $15 \mathrm{~s} \leq t \leq 30 \mathrm{~s}$, in which the wave generation is stabilized and there is no influence of wave reflection.

In Tab. 4 the mass flow rate average values until case 4 are almost constant, but from case 4 a more significant difference can be observed. As the OWC converter in all six cases is submitted to the incidence of the same regular waves, the mass flow rate should be constant. 
Table 4 Results considering the physical restriction diameter (real scale).

\begin{tabular}{|c|c|c|c|}
\hline $\begin{array}{c}\text { Physical } \\
\text { Restriction }\end{array}$ & $\begin{array}{c}\text { Mass flow } \\
(\mathrm{kg} / \mathrm{s})\end{array}$ & $\begin{array}{c}\text { Pressure } \\
\text { drop (Pa) }\end{array}$ & $\begin{array}{c}\text { Power } \\
(\mathrm{W})\end{array}$ \\
\hline 1 & 16.44 & 64.86 & 201.26 \\
\hline 2 & 16.43 & 68.43 & 220.94 \\
\hline 3 & 16.41 & 76.04 & 267.86 \\
\hline 4 & 16.36 & 98.44 & 415.46 \\
\hline 5 & 16.07 & 224.36 & $1,254.37$ \\
\hline 6 & 11.23 & $2,162.11$ & $8,633.11$ \\
\hline
\end{tabular}

However, the variation of this quantity noted in the results of Tab. 4 must be caused by the increasing of the physical restriction, which causes an air flow damping. As a consequence, the pressure and the power also increase as can be seen in Fig. 9. Therefore, the results showed that, among the studied cases, the case 4 as the most appropriate physical restriction.

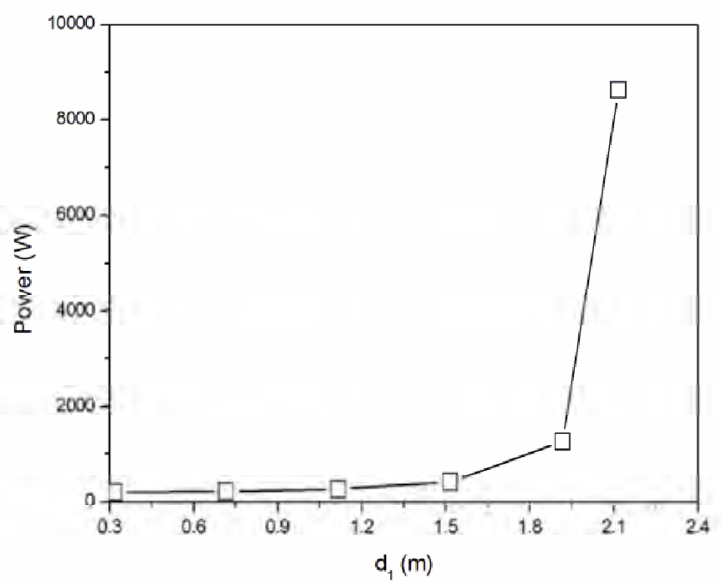

Fig. 9 Power variation as a function of the physical constraint diameter (rotor hub geometry).

Other consideration that can be made to corroborate the choice of case 4 as the best shape is related with the turbine design. If the difference between the chimney outlet length $(l)$ and the physical restriction diameter $\left(d_{1}\right)$ of case 4 is evaluated, a gap of $0.8 \mathrm{~m}$ is encountered representing a clearance around $35 \%$ of the $l$ dimension.

So, using the computational domain of case 4 and the wave spectrum presented in Tab. 2, it was possible to investigate the fluid-dynamic behavior of the OWC converter taking into account the pressure drop imposed by the turbine. Here, the average values were also obtained by RMS technique during an interval time of $15 \mathrm{~s} \leq t \leq 30 \mathrm{~s}$. In Tab. 5 these values are showed, while in Tab. 6 the pressure and flow rate non dimensional coefficients, defined by Eqs. (6) and (7), respectively, are also presented. It is important to mention that in Eqs. (6) and (7) the speed of the turbine rotation was $157.1 \mathrm{rad} / \mathrm{s}$ (1500 RPM), in agreement with Weber and Thomas (2001).

Table 5 indicates that the increase of the wave period promotes a reduction in all quantities analyzed, being this trend also observed in Liu (2009).
Finally, in Fig. 10, a graph relating the pressure and flow coefficients are obtained from the numerical simulations. One can note a linear trend between these coefficients, which is a typical characteristic of a Wells turbine. So, if a linear fit is applied, as performed in Weber and Thomas (2001), the following relation is obtained: $\Phi=0.1017 \Psi$, having this value the same order of magnitude of that presented in Weber e Thomas (2001).

Table 5 Numerical results form wave spectrum analysis.

\begin{tabular}{|c|c|c|c|c|}
\hline Wave & $\begin{array}{c}\text { Volumetric } \\
\text { flow rate } \\
{\left[\mathbf{m}^{\mathbf{3}} / \mathbf{s}\right]}\end{array}$ & $\begin{array}{c}\text { Pressure } \\
{[\mathbf{P a}]}\end{array}$ & $\begin{array}{c}\text { Mass flow } \\
\text { rate }[\mathbf{K g} / \mathbf{s}]\end{array}$ & $\begin{array}{c}\text { Power } \\
{[\mathbf{W}]}\end{array}$ \\
\hline 1 & 13.35 & 83.55 & 16.36 & 415.46 \\
\hline 2 & 13.72 & 82.02 & 16.81 & 458.11 \\
\hline 3 & 12.29 & 66.21 & 15.05 & 364.07 \\
\hline 4 & 10.77 & 53.85 & 13.20 & 270.81 \\
\hline 6 & 8.26 & 35.02 & 10.12 & 144.91 \\
\hline 7 & 7.36 & 28.49 & 9.10 & 110.08 \\
\hline 8 & 6.66 & 24.62 & 8.16 & 86.84 \\
\hline
\end{tabular}

Table 6 Dimensionless pressure and flow coefficients.

\begin{tabular}{|c|c|c|}
\hline Wave & $\begin{array}{c}\text { Flow rate coefficient } \\
\Phi\end{array}$ & $\begin{array}{c}\text { Pressure coefficient } \\
\Psi\end{array}$ \\
\hline 1 & 0.00682 & 0.00051 \\
\hline 2 & 0.00701 & 0.00050 \\
\hline 3 & 0.00628 & 0.00040 \\
\hline 4 & 0.00550 & 0.00033 \\
\hline 6 & 0.00422 & 0.00021 \\
\hline 7 & 0.00379 & 0.00017 \\
\hline 8 & 0.00340 & 0.00015 \\
\hline
\end{tabular}

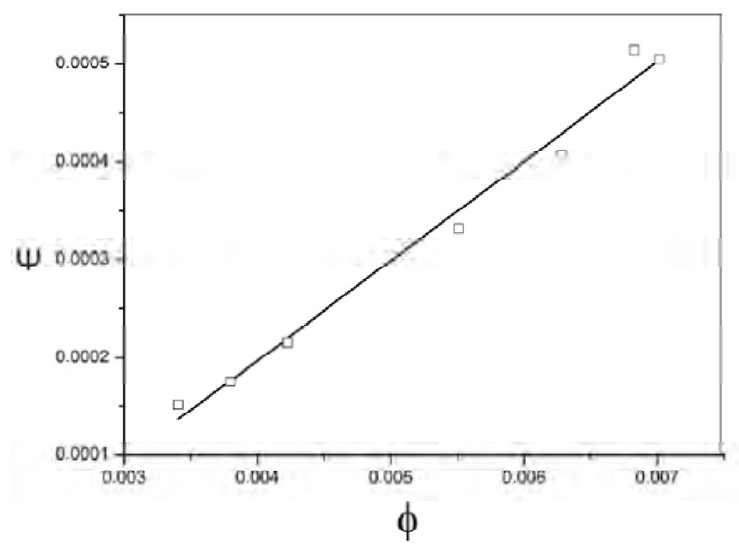

Fig. 10 Pressure coefficient versus flow rate coeficcient - Strategy 2.

Therefore, considering all discussed aspects it is possible to state that the use of a physical restriction to represent the 
pressure drop imposed by the turbine over the air flow in an OWC converter computational model can be employed in a satisfactory way, especially for consideration of the turbine effect over the fluid flow inside the chamber and for geometry design of the device.

\section{Conclusions}

This work presented two strategies which can be used in the computational modeling of the operating principle of an OWC converter, aiming to impose over the air flow, by means of a physical constraint, the pressure drop that in practice would be generated by the presence of the turbine. In the first strategy a restriction similar to an orifice plate was considered. In the second approach a restriction with a geometry similar to a turbine rotor hub was taking into account.

The obtained results, although in an initial stage, are very promising, because it was possible to analyze the fluiddynamic OWC behavior in a more realistic way. The pressure drop caused by the restriction causes velocity and pressure variations in the air flow similar to those noticed in a real OWC converter.

The results also showed that the numerical method proposed here led to a behavior of the effect of the flow coefficient over the pressure drop and over the PTO similar to those obtained into archival literature, allowing its future application for achievement of theoretical recommendations concerned with the design of the device.

\section{Acknow ledgements}

E. D. dos Santos thanks FAPERGS by financial support (Process: 12/1418-4). L. A. O. Rocha thanks CNPq by research grant. F. M. Seibt thanks CAPES by scholarship.

\section{References}

Chakrabarti, S. K., (2005) - "Handbook of offshore engineering". v. 1, Elsevier, Ilinois, USA, 661 p.

CruZ, J. M. B. P. and Sarmento, A. J. N. A., (2004) - "Energia das Ondas: Introdução aos Aspectos Tecnológicos, Econômicos e Ambientais". Alfragide: Instituto do Ambiente.
CARIJA, Z., Kranjcevic, Banic,V., Cravak, M., (2012) "Numerical analysis of wells turbine for wave power conversion". Engineering Review, v. 3, n. 3, pp. 141-146.

Dos Santos, E. D., Machado, B. N., Lopes, N. R., Souza, J. A., Teixeira, P. R. F., Gomes, M. das N., Isoldi, L. A., Rocha, L. A. O. (2013) - "Constructal Design of Wave Energy Converters". In: Rocha, L. A. O., Lorente, S., Bejan, A. (Eds.), Constructal Law and the Unifying Principle of Design, Springer, New York, pp. 275-294.

FLUENT, (2007) - "User's Manual". ANSYS, Inc.

Gomes, M. das N., Olinto, C. R., Rocha, L. A. O., Souza, J. A. and Isoldi, L. A., (2009) - "Computational modeling of a regular wave tank". Engenharia Térmica, v. 8, pp. 44-50.

Gomes, M. das N., (2010) - "Modelagem Computacional de um Dispositivo Coluna d'Água Oscilante de Conversão de Energia das Ondas do Mar em Energia Elétrica". Master Thesis in Computational Modeling, Federal University of Rio Grande, Brazil, 187 p.

Gomes, M. das N., Nascimento, C. D., Bonafini, B. L., Dos Santos, E. D, Isoldi, L. A. and Rocha, L. A. O., (2012) "Two-dimensional geometric optimization of an oscillating water column converter in laboratory scale". Engenharia Térmica, v.11, pp. 30-36.

Gomes, M. das N., Dos Santos, E. D, Isoldi, L. A. and Rocha, L. A. O., (2013) - "Two-dimensional geometric optimization of an oscillating water column converter of real scale". In: $22^{\text {nd }}$ International Congress of Mechanical Engineering (COBEM), Ibero Latin American Congress on Computational Methods in Engineering (CILAMCE), pp. 1-12.

Grimmler, J. do A. M., Gomes, M. das N., Souza, J. A., dos Santos, E. D., Rocha, L. A. O. and Isoldi, L. A., (2012) "Constructal Design of a Three-Dimensional Oscillating Water Column (OWC) Wave Energy Converter (WEC)". International Journal of Advanced Renewable Energy Research, v. 1, n. 9, pp. 573-580.

HIRT, C. W. and Nichols, B. D., (1981) - "Volume of fluid (VOF) method for the dynamics of free boundaries". Journal of Computational Physics, v. 39, n. 1, pp. 201-225.

Horko, M., (2007) - "CFD Optimisation of an Oscillating Water Column Energy Converter". Master Thesis in Engineering ans Science, Scholl of Mechanical Engineering, University of Western, Australia, $145 \mathrm{p}$.

Khaligh, A. and Onar, O. C., (2010) - "Energy Harvesting: Solar, Wind, and Ocean Energy Conversion Systems". CRC Press, $341 \mathrm{p}$.

LiU, Z.; Hyun B.; Hong, K., (2008a) - "Application of Numerical Wave Tank to OWC Air Chamber for Wave Energy Conversion". International Offshore and Polar Engineering Conference. 
LiU, Z.; Hyun B.; Jin, J., (2008b) - "Numerical prediction for overtopping performance of OWEC". Journal of the Korean Society for Marine Environmental Engineering, v. 11, n.1, p. 35-41.

LiU, Z. ; Hyun, B. S.; Hong, K. and Lee, Y., (2009) "Investigation on integrated system of chamber and turbine for OWC wave energy convertor". In: Proceeding of the nineteenth international offshore and polar engineering conference, pp. 276-282.

Liu, Z.; Hyun B.; Hong, K., (2011) - "Numerical study of air chamber for oscillating water column wave energy convertor". China Ocean Eng., v. 25, pp. 169-178.

Nielsen F. G., Andersen M., Argyriadis K., Butterfield S., Fonseca N., Kuroiwa T., Boulluec M. L., Liao S-J., Turnock S. R. and Waegter J., (2006) - "Ocean wind and wave energy utilization". ISSC.

Ramalhais, R. dos S., (2011) - "Estudo numérico de um dispositivo de conversão da energia das ondas do tipo coluna de água oscilante (CAO)". Dissertação (Mestrado em Engenharia Mecânica) - Faculdade de Ciências e Tecnologia da Universidade Nova de Lisboa, Lisboa, Portugal, 107 p.
Seibt, F. M., Couto, E. C., Santos, E. D. dos, Isoldi, L. A., Rocha, L. A. O. and Teixeira, P. R. de F., (2013) "Numerical Study on the Effect of Submerged Depth on Horizontal Plate Wave Energy Converter". China Ocean Engineering (in press).

SRINIVASAN, V., Salazar, A. J. and Saito, K., (2011) "Modeling the disintegration of modulated liquid jets using volume-of-fluid (VOF) methodology". Applied Mathematical Modeling, v. 35, n. 8, pp. 3710-3730.

Twidell, J. and Weir, T., (2006) - "Renewable Energy Resources". 2. ed., Taylor \& Francis, 607 p.

Versteeg, H. K., and Malalasekera, W., (2007) - "An Introduction to Computational Fluid Dynamics". 2. ed., Pearson, p. 503.

Weber, J. W. and Thomas, G. P., (2001) - "An investigation into the importance of the air chamber deign of an oscillating water column wave energy device". In: Proceeding of the eleventh international offshore and polar engineering conference, pp. 581-588. 